\title{
Mapping of a Myosin-binding Domain and a Regulatory Phosphorylation Site in M-Protein, a Structural Protein of the Sarcomeric M Band
}

\author{
Wolfgang M.J. Obermann, ${ }^{*}$ Peter F.M. van der Ven, ${ }^{*+}$ Frank Steiner, \\ Klaus Weber, ${ }^{*}$ and Dieter O. Fürst ${ }^{\text {tł }}$ \\ *Max-Planck-Institute for Biophysical Chemistry, Department of Biochemistry, D-37077 Göttingen, \\ Germany; and 'University of Potsdam, Department of Cell Biology, D-14471 Potsdam, Germany
}

Submitted August 4, 1997; Accepted January 20, 1998

Monitoring Editor: Thomas D. Pollard

\begin{abstract}
The myofibrils of cross-striated muscle fibers contain in their $\mathrm{M}$ bands cytoskeletal proteins whose main function seems to be the stabilization of the three-dimensional arrangement of thick filaments. We identified two immunoglobin domains (Mp2-Mp3) of M-protein as a site binding to the central region of light meromyosin. This binding is regulated in vitro by phosphorylation of a single serine residue (Ser76) in the immediately adjacent amino-terminal domain Mp1. M-protein phosphorylation by cAMP-dependent kinase A inhibits binding to myosin LMM. Transient transfection studies of cultured cells revealed that the myosin-binding site seems involved in the targeting of M-protein to its location in the myofibril. Using the same method, a second myofibrilbinding site was uncovered in domains Mp9-Mp13. These results support the view that specific phosphorylation events could be also important for the control of sarcomeric $\mathrm{M}$ band formation and remodeling.
\end{abstract}

\section{INTRODUCTION}

Thick and thin myofilaments, the major structural and functional entities of cross-striated myofibrils, are kept in their remarkably stable and regular arrangement by a highly complex cytoskeleton (see, for example, review by Small et al., 1992). While thin filaments are organized by the Z-discs, the hexagonal thick filament lattice seems cross-linked in the central bare zone by bridging structures, the so-called M-bridges and Mfilaments (Luther and Squire, 1978).

Until now, only a small group of proteins has been shown to be true $\mathrm{M}$ band constituents. MM creatine kinase is thought to be the component that makes up the M4-M4' bridges (Wallimann et al., 1983; Wallimann and Eppenberger, 1985). It is not yet clear whether, in addition to its obvious role in energy metabolism, MM creatine kinase is also involved in the linkage of thick filaments. Three structural proteins were revealed as true $\mathrm{M}$ band constituents: $\mathrm{M}$ -

\footnotetext{
$\ddagger$ Corresponding author: University of Potsdam, Department of Cell Biology, Lennéstrasse 7a, D-14471 Potsdam, Germany.
}

protein (Masaki and Takaiti, 1974), myomesin (Grove et al., 1984), and titin (Nave et al., 1989; Vinkemeier et al., 1993). Immunofluorescence studies revealed striking differences in embryonic expression patterns of these proteins: while both titin and myomesin are expressed from the earliest stages of myocyte differentiation (Grove et al., 1985; Fürst et al., 1989; Carlsson et al., 1990), M-protein shows a stage- and tissuespecific distinct redistribution. First, M-protein is transiently expressed in all fetal cross-striated muscle fibers. It is subsequently suppressed in skeletal muscle fibers around birth and finally is reexpressed in adult type-II fibers (Grove et al., 1985, 1987; Carlsson et al., 1990). Recently, the use of a panel of sequence-assigned antibodies in immunoelectron microscopy allowed the proposal of a structural model that describes the layout of titin, myomesin, and M-protein in the sarcomeric $\mathrm{M}$ band. Both titin and myomesin are arranged largely in an antiparallel and staggered manner, while M-protein seems to bridge the thick filaments essentially in a perpendicular direction (Obermann et al., 1996). 
Although M-protein has been known for a long time and protocols for its purification did exist, it has been remarkably difficult to describe, at the molecular level, its binding to other myofibrillar proteins. Studies performed independently by three different groups concluded "that such interactions are either weak or absent in vitro" (Mani and Kay, 1978; Woodhead and Lowey, 1983; Bähler et al., 1985). We addressed this question by producing a panel of recombinant Mprotein and myosin-rod fragments. Purified recombinant proteins were subsequently used to search for respective binding sites. These experiments identified M-protein domains Mp2 to Mp3 as myosin-binding site and showed that this interaction can be regulated by phosphorylation.

\section{MATERIALS AND METHODS}

\section{Expression of M-Protein Fragments in Escherichia coli}

Partial M-protein sequences were amplified by polymerase chain reaction (PCR) (Saiki et al., 1985) using the full-length human cDNA (Vinkemeier et al., 1993) as a template. PCR products were cloned into a pET23a vector derivative. This provided the recombinant protein fragments with a carboxy-terminally located $\mathrm{His}_{6}$ sequence followed by an EEF-tag that can be detected with a monoclonal antibody. Subsequent to growth of E. coli BL21(DE3)pLysS cells (Studier et al., 1990) at $\mathrm{OD}_{600}=1.0$ in LB medium supplemented with $2 \%$ glucose, $100 \mu \mathrm{g} / \mathrm{ml}$ ampicillin, and $34 \mu \mathrm{g} / \mathrm{ml}$ chloramphenicol and induction for $4 \mathrm{~h}$ at $18^{\circ} \mathrm{C}$ with $0.15 \mathrm{mM} \mathrm{IPTG}{ }^{1}$, bacteria were harvested and stored at $-70^{\circ} \mathrm{C}$ until use. Pellets were resuspended and sonicated in buffer $\mathrm{A}(50 \mathrm{mM}$ potassium phosphate, $\mathrm{pH}$ 8.0, $500 \mathrm{mM} \mathrm{KCl}, 0.2 \%$ Tween-20, $5 \mathrm{mM}$ 2-mercaptoethanol) containing $5 \mu \mathrm{M}$ E64 and $1 \mathrm{mM}$ PMSF as protease inhibitors. After centrifugation at $16,000 \times g$, soluble recombinant proteins were enriched by metal chelate affinity chromatography. Briefly, protein solutions were applied onto Ni-NTA-agarose columns (Qiagen, Hilden, Germany), which were washed with buffer A and subsequently with buffer B (same as buffer A, except pH 6.0). Finally, the recombinant proteins were eluted with $500 \mathrm{mM}$ imidazole in buffer B. After dialysis against buffer C (50 mM Tris-HCl, pH 7.9, $1 \mathrm{mM}$ EDTA, $1 \mathrm{mM}$ DTT) recombinant proteins were purified to homogeneity by ion exchange chromatography on MonoQ FPLC columns (Pharmacia, Uppsala, Sweden). Integrity of the purified proteins was monitored by $\mathrm{N}$-terminal sequencing and the reaction with the EEF-tag specific antibody YL1/2 (Wehland et al., 1984).

\section{Mutagenesis}

Serine to alanine mutations were introduced into the M-protein Mp1-5 fragment by PCR amplification with mismatch oligonucleotides resulting in site-directed exchanges of serine to alanine codons following the method of Ausubel et al., 1995). Amplified fragments were subcloned into pET-23a- derived expression vectors and the eukaryotic expression vector pCMV5/T7 (see below). DNA sequencing established the original sequence and the desired Ser/Ala exchanges.

${ }^{1}$ Abbreviations used: DTT, dithiothreitol; E64, trans-epoxysuccinyl-L-leucylamido-(4-guanidino) butane; IPTG, isopropyl $\beta$-D $[R]$-Thiogalactopyranoside; LMM, light meromyosin; MES, 2-[N-morpholino] ethane sulfonic acid; PKA, cAMP-dependent protein kinase A; PMSF, phenylmethylsulfonyl fluoride.

\section{Recombinant Fragments of Myosin}

Different portions of rabbit fast skeletal muscle LMM were amplified by PCR using the original cDNA of rabbit myosin heavy chain-2/10 (Maeda et al., 1987) as a template. Four constructs were designed, in which the carboxy termini were identical with the end of the original clone (i.e., amino acid residue 1939). The amino termini were placed at different points along the sequence of the myosin rod portion. This resulted in a series of "shorter LMMs," which were designated according to their approximate molecular masses (in kilodaltons): LMM75 (corresponding to residues 12841939 of the original clone; Maeda et al., 1987), LMM59 (residues 1429-1939), LMM50 (residues 1506-1939), and LMM30 (residues 1675-1939). In addition, a construct, called LMM75-50, was made. It corresponds to the amino-terminal portion of LMM and represents residues 1284-1505 of the myosin heavy chain sequence. For the positions of these constructs on the myosin rod, see also the schematic representation in Figure 1. PCR products were cloned into the pET-23a expression vector (Novagen, Heidelberg, Germany). Recombinant LMM fragments were expressed in E. coli BL21(DE3)pLysS and purified by two high-salt/low-salt extraction and precipitation cycles as described (Maeda et al., 1987). All recombinant LMM fragments formed normal paracrystals as judged by electron microscopic inspection after negative staining (our unpublished results; Maeda et al., 1987).

\section{Preparation of Native Proteins from Bovine Skeletal Muscle}

Myosin rod and LMM were prepared as described (Obermann et al. 1995). Purification of bovine M-protein was performed as reported (Vinkemeier et al., 1993). Preparation of proteolytic M-protein fragments obtained by endoproteinase Asp-N, endoproteinase Lys-C, and trypsin was as described for myomesin (Obermann et al., 1995). Digests were stopped by the addition of PMSF (endoproteinase Lys-C and trypsin) or EDTA (endoproteinase Asp-N). Resulting peptides were separated by gel permeation chromatography using a Superose $12 \mathrm{HR}$ 10/30 FPLC column equilibrated in $50 \mathrm{mM}$ Tris-HCl, pH 7.9, $500 \mathrm{mM} \mathrm{KCl}, 1 \mathrm{mM}$ EDTA, and $1 \mathrm{mM}$ DTT.

\section{Phosphorylation of Proteins and Synthetic Peptides}

Purified M-protein as well as its proteolytic trypsin fragment and recombinant $\mathrm{M}$-protein fragments were added at a final concentration of $0.2 \mu \mathrm{g} / \mathrm{ml}$ to $20 \mu \mathrm{l}$ of assay buffer (50 mM MES, pH 6.9, 100 $\mathrm{mM} \mathrm{KCl}, 2 \mathrm{mM} \mathrm{MgCl}$ ). Phosphorylation reactions were at $30^{\circ} \mathrm{C}$ for 30 min with $1 \mathrm{U}$ protein kinase A from porcine heart (Sigma Chemical, St. Louis, MO) or $1 \mu \mathrm{l}$ of muscle extract and $1 \mu \mathrm{Ci}\left[\gamma_{-}{ }^{32} \mathrm{P}\right] \mathrm{ATP}$ $(3000 \mathrm{Ci} / \mathrm{mmol}$, Amersham, Arlington Heights, IL). After addition of sample buffer (Laemmli, 1970) and heating to $65^{\circ} \mathrm{C}$ for $10 \mathrm{~min}$, polypeptides were analyzed by $4-12 \%$ or $6-20 \%$ SDS-PAGE. Gels were dried, and autoradiography was performed at $-80^{\circ} \mathrm{C}$ with intensifying screens. For a quantification of the phosphorylation, bands from individual assays were cut out of the gels and homogenized. Gel fragments were suspended in "Ready Safe" (Beckman, Fullerton, CA) and measured in a Beckman LS 8100 liquid scintillation counter. Means of the incorporated counts were calculated from three independent experiments.

Synthetic peptides were phosphorylated for kinetic experiments essentially as described previously (Kemp et al., 1977). Briefly, the reaction mixture (total volume, $70 \mu \mathrm{l}$ ) contained the respective peptide at concentrations ranging from 0.1 to $1.5 \mathrm{mM}$ in the following solution: $10 \mu \mathrm{Ci}\left[\gamma^{-32} \mathrm{P}\right] \mathrm{ATP}(0.5 \mathrm{mM}), 62.5 \mathrm{mM} \mathrm{MES}, \mathrm{pH} 6.9$, $12.5 \mathrm{mM}$ magnesium acetate, $0.25 \mathrm{mM}$ EGTA, and either protein kinase A (catalytic subunit, Boehringer, Mannheim, Germany) or sarcomeric muscle extracts prepared as described previously (Obermann et al., 1997). Subsequent to incubation at $37^{\circ} \mathrm{C}$ for $0,1,2,5,10$, and $15 \mathrm{~min}, 8-\mu \mathrm{l}$ aliquots were removed from the reaction and phosphorylated peptides were separated from $\left[\gamma^{-32} \mathrm{P}\right] \mathrm{ATP}$ by the phosphocellulose binding technique (Casnellie, 1991). Apparent $K_{\mathrm{m}}$ 
and $\mathrm{V}_{\max }$ values were determined by fitting the data of a doublereciprocal Lineweaver-Burk plot to the Michaelis-Menten equation using the method of least squares.

\section{Phosphoamino Acid Analysis}

${ }^{32} \mathrm{P}$-labeled protein was recovered from sample buffer by the method of Wessel and Flügge (1984), dried, and hydrolyzed in $6 \mathrm{M}$ $\mathrm{HCl}$ at $110^{\circ} \mathrm{C}$ for $2 \mathrm{~h}$. After lyophylization the hydrolysate was dissolved in $10 \mu \mathrm{l} \mathrm{H}_{2} \mathrm{O}$ and applied to a Polygram CEL400 Uni layer plate (Merck, Darmstadt, Germany). Electrophoretic separation of phosphoamino acids was in $10 \%$ acetic acid, $1 \%$ pyridin, $\mathrm{pH} 3.5$, at $800 \mathrm{~V}$ for $1 \mathrm{~h}$. Radioactively labeled phosphoamino acids were identified by visualization of standard phosphoamino acids with ninhydrin and autoradiography.

\section{Myosin-binding Assays}

M-protein was treated with endoproteinase Asp-N (see above), and the digest was subjected to gel filtration on a Superose 12 HR10/30 column. One microliter of each fraction was spotted onto nitrocellulose membranes (BA 85, Schleicher \& Schüll, Dassel, Germany). After air drying, the strips were blocked with overlay buffer $(1 \%$ BSA, $0.2 \%$ Tween 20, $100 \mathrm{mM} \mathrm{KCl}, 20 \mathrm{mM}$ imidazole- $\mathrm{HCl} \mathrm{pH} 7.0,1$ $\mathrm{mM}$ DTT) for $30 \mathrm{~min}$. Purified LMM and recombinant LMM-30 were biotinylated (NHS-LC-Biotinylation kit, Pierce, Rockford Chemical, Rockford, IL) following the instructions of the manufacturer, diluted to $0.1 \mathrm{mg} / \mathrm{ml}$ in overlay buffer, and used to treat the blocked strips for $60 \mathrm{~min}$. After three washes with overlay buffer, the strips were incubated for $30 \mathrm{~min}$ with an avidin-biotin-peroxidase complex (ABC Peroxidase staining kit, Pierce). After a final washing cycle, binding of LMM to M-protein fragments was visualized by reaction in $5 \mathrm{ml}$ of $100 \mathrm{mM}$ Tris- $\mathrm{HCl}, \mathrm{pH} 7.5$, supplemented with $100 \mu \mathrm{l}$ diaminobenzidine ( $40 \mathrm{mg} / \mathrm{ml}$ stock), $25 \mu \mathrm{l} \mathrm{NiCl}{ }_{2}$

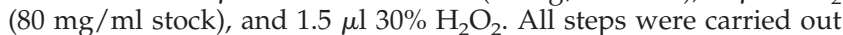
at room temperature.

In the case of recombinant M-protein fragments, both $\alpha$-chymotryptic myosin subfragments (myosin rod and LMM) and recombinant LMM fragments (LMM75, LMM59, LMM50, LMM50-75, LMM30) were dialyzed to $50 \mathrm{mM} \mathrm{KCl}, 5 \mathrm{mM}$ Na-phosphate, $\mathrm{pH} 7.0$, to allow the formation of filaments. Approximately $1 \mu \mathrm{g}$ of each suspension was spotted onto nitrocellulose membranes. All subsequent steps were as described above expect that individual strips were incubated for $60 \mathrm{~min}$ with the respective M-protein fragments dissolved in overlay buffer, and detection was with rat monoclonal antibody YL1/2 (Wehland et al., 1984) specific for the EEF-tag of our recombinant fragments (see Obermann et al., 1997).

\section{Construction of the pCMV5-T7 Vector and of Recombinant Constructs}

pCMV5 vector was a generous gift from Dr. V. Gerke (MPI, Göttingen). Its polycloning site was excised by digestion with restriction enzymes EcoRI and SmaI and was replaced by a new cassette containing, from $5^{\prime}$ to $3^{\prime}$, the following restriction enzyme sites: BamHI, $M l u \mathrm{I}$, HindIII, SalI. This polylinker was followed by a sequence encoding the 12-amino acids long T7-tag MASMTGGQQMGR (Lutz-Freyermuth et al., 1990; Tsai et al., 1992) and an in-frame stop codon. The T7-tag peptide is recognized by a specific monoclonal antibody that was purchased from Novagen (Heidelberg, Germany) Desired M-protein fragments were amplified by PCR (Saiki et al., 1985) using sense primers containing an $M l u \mathrm{I}$ site and antisense primers containing a SalI site adjacent to a matching sequence of 30 bp derived from the human cDNA (Vinkemeier et al., 1993). Resulting PCR fragments were double digested with MluI and SalI and ligated to the correspondingly cut $\mathrm{PCMV5-T7}$ vector following standard protocols (Sambrook et al., 1989). Plasmids were propagated in JM 109 bacteria, and the DNA was purified on Qiagen columns (Qiagen, Hilden, Germany).

\section{Cell Culture and Transfections}

BHK-21/C13 and C2C12 cells were cultured in DMEM supplemented with $2 \mathrm{mM}$ L-glutamine, antibiotics $(100 \mathrm{U} / \mathrm{ml}$ penicillin and $1 \mu \mathrm{g} / \mathrm{ml}$ streptomycin), and 10\% FCS (BHK) or $15 \%$ FCS (C2C12), all from Life Technologies (Eggenstein, Germany). Approximately $8 \mathrm{~h}$ before transfection, cells were seeded on glass coverslips at a density that resulted in $40-50 \%$ confluency at the time of transfection. The cells were transfected with the recombinant pCMV5/T7 constructs using a modification of the calcium phosphate precipitation method (Sambrook et al., 1989). Briefly, after incubation with the transfection mixture for $16 \mathrm{~h}$, the cells were washed with PBS and glycerol shocked for 2 min using 15\% glycerol in culture medium. Fresh medium was subsequently added. At different time intervals after transfection, cells were fixed for $10 \mathrm{~min}$ in 3\% paraformaldehyde in PBS and permeabilized for $10 \mathrm{~min}$ in $0.5 \%$ Triton X-100 in PBS. After being rinsed with PBS, the specimens were used in immunofluorescence assays or stored in PBS at $4^{\circ} \mathrm{C}$ until use. Alternatively, the culture medium was replaced by a low-nutrition medium (DMEM, L-glutamine and antibiotics as above, and $0.4 \%$ Ultroser G [Life Technologies]), to induce differentiation in both cell types. Between 1 and $6 \mathrm{~d}$ after this medium change, cells were fixed and permeabilized as described above.

\section{Immunohistochemistry}

Fixed and permeabilized transfected cells were rinsed with PBS/ $0.05 \%$ Tween 20 (PBST) and incubated with an antibody directed against the T7 tag (immunoglobin G2b [IgG2b]; Novagen). In some experiments the cells were double-stained using standard procedures (Van der Ven et al., 1993) with the T7 tag antibody and an M-protein domain-specific antibody (MpAA259, IgA: Obermann et al., 1996), a titin antibody (9D10, IgM: Wang and Greaser, 1985), or tetramethylrhodamine-5-isothiocyanate-conjugated phalloidin (Sigma, Deisenhofen, Germany) to identify F-actin. The appropriate Ig subtype-specific fluorescein isothiocyanate- or Texas Red-conjugated secondary antibodies were purchased from Southern Biotechnology Associates (Birmingham, AL). They were diluted in PBST according to the recommendations of the manufacturer.

\section{Miscellaneous Procedures}

Protein concentrations were determined with the Bio-Rad dye reagent (Bio-Rad, Richmond, CA). Synthetic peptides were obtained by Fmoc chemistry on a Pep Synthesizer TM9050 (Millipore, Bedford, MA). Microsequencing was done as reported (Obermann, et al., 1995). All DNA cloning steps followed standard protocols (Ausubel et al., 1995, Sambrook et al., 1989). SDS-PAGE and immunoblotting were as described previously (Fürst et al., 1988).

\section{RESULTS}

\section{M-protein Domains Mp1 to Mp2 Interact with Myosin Filaments in Vitro}

To locate the myosin-binding site of M-protein, we used limited proteolysis of the purified bovine protein to produce defined subfragments. Most revealing was cleavage with endoproteinase AspN, which provided a $\sim 45-\mathrm{kDa}$ fragment and a $\sim 110-\mathrm{kDa}$ fragment (arrows in Figure 2A). Microsequencing located their amino termini to Glu136 and Glu496 of the translated human cDNA sequence. Thus, the $45-\mathrm{kDa}$ fragment comprises essentially domains $\mathrm{Mp} 2$ to Mp4, and the $110-\mathrm{kDa}$ fragment covers the carboxy-terminally situated remainder of the molecule (for domain designations see sketch in Figure 1). The two fragments were 


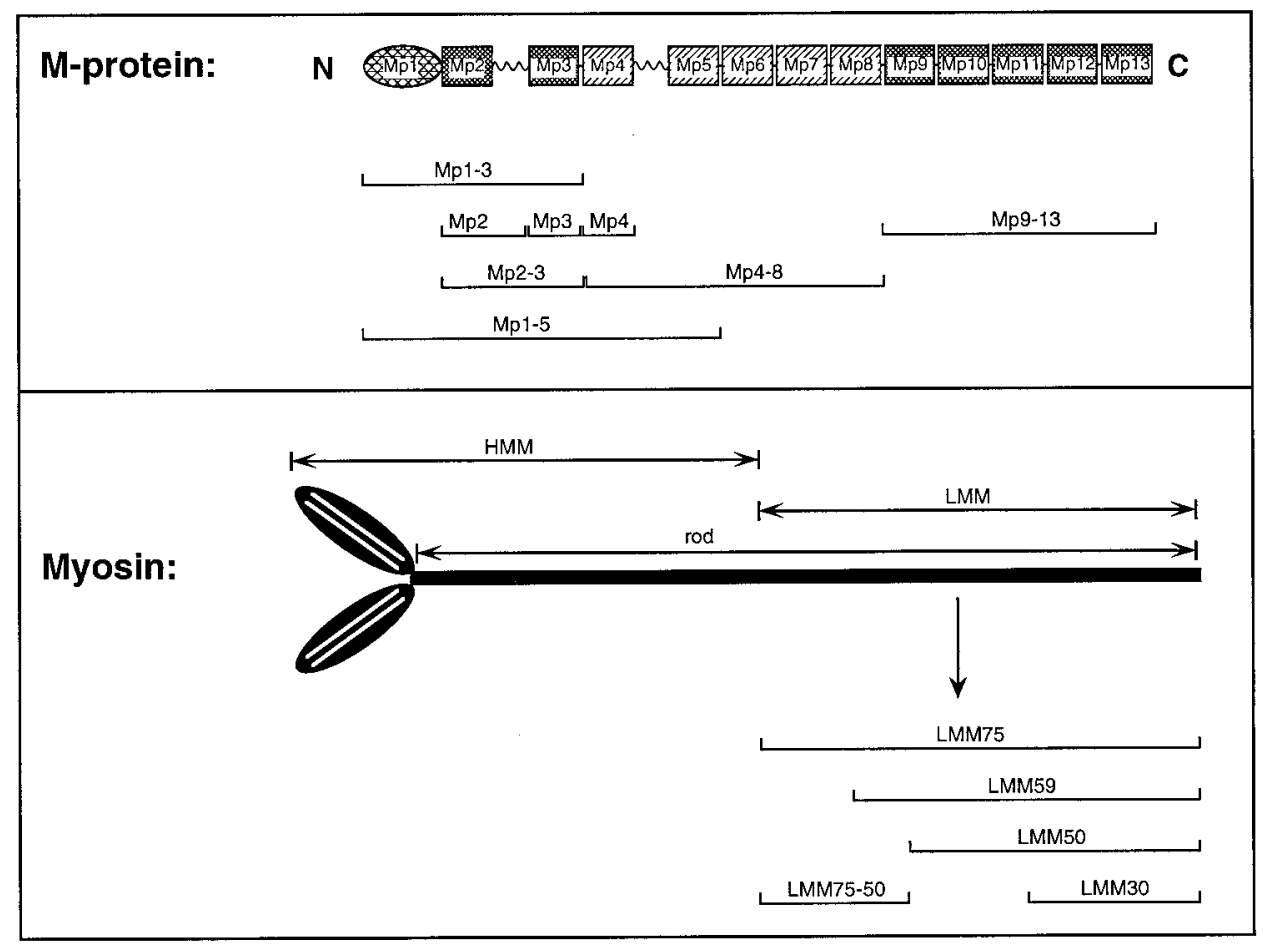

Figure 1. Summary diagram giving a schematic representation of the domain organizations for $\mathrm{M}$ protein and for myosin. The presentation emphasizes the modular construction of M-protein from repetitive Ig cII (cross-hatched rectangles) and fibronectin type III repeats (shaded rectangles) interspersed by unique sequence stretches of varying length. Recombinant constructs used for mapping of binding sites, transfection of cultured myoblasts, and phosphorylation assays are marked by brackets. The location of the most prominent proteolytic fragments of myosin is given in the lower panel above the myosin sketch. Brackets indicate the borders of the recombinant LMM constructs used in this study. separated by gel filtration chromatography (Figure 2A). Column fractions were used in solid-phase overlay assays to investigate the interaction of the fragments with myosin rod and LMM-30. Clearly, only the smaller, amino-terminally situated $45-\mathrm{kDa}$ fragment of M-protein (residues 147-496) exhibited binding to myosin (Figure 2B).

For a more precise mapping of mutual binding sites in M-protein and myosin, we produced a series of recombinant M-protein constructs as well as proteolytic and recombinant derivatives of myosin. The sketch in Figure 1 describes the location of all the constructs of the two proteins used in this study. Figure 3A monitors the purity of the M-protein fragments, while the purity of the myosin derivatives was described recently (Obermann et al., 1997). Several constructs representing distinct portions of the Mp2 to Mp4 region of M-protein were employed in solidphase myosin-binding assays. Figure 3B shows that only a fragment comprising the two Ig domains Mp2Mp3 exhibited a concentration-dependent interaction with myosin. In contrast, none of the single domains was able to bind to myosin. Since in the Mp2 construct the linker region connecting the domains Mp2 and Mp3 was contained, we can also exclude the possibility that this linker alone could constitute the binding site. This suggests that the two M-protein domains Mp2-Mp3 constitute the minimal myosin-binding site of M-protein.

\section{M-protein Is Phosphorylated by PKA in the Amino- terminal Domain Mp1}

M-protein bears a unique amino-terminal domain (Mp1; 151 residues) and 12 repeat domains of either the Ig cII and fibronectin type III class (Vinkemeier, et al., 1993). Detailed computer analysis of the translated human cDNA sequence predicted two target sites for cAMP-dependent PKA: Ser39 in the motif KKRAS and Ser76 in the sequence KRVS. To analyze whether one or both of these serine residues can be phosphorylated in the native protein, we incubated purified bovine M-protein with PKA in the presence of $\left[\gamma^{32} \mathrm{P}\right] \mathrm{ATP}$. Figure 4 documents the phosphorylation of M-protein by PKA (Figure $4 \mathrm{~A}$, lane 1 , and Figure $4 \mathrm{~B}$, lane 1 ). For a preliminary mapping of the phosphorylation site(s), we subjected M-protein to limited proteolysis by trypsin and isolated a stable fragment comprising domains Mp6-Mp13 (established by microsequencing). Since this fragment cannot be phosphorylated by PKA (Figure 4B), the phosphorylation site(s) must lie in Mp1Mp5. Furthermore, we used a digest of M-protein with endoproteinase AspN. This yielded two fragments comprising domains Mp2-Mp4 and Mp5-Mp13, respectively (see Figure 2A). Since neither fragment can be phosphorylated, we concluded that the phosphorylation site must be located in the unique amino terminus and possibly involves the predicted sites in domain Mp1 (Figure 4, A and B). Phosphoamino acid analysis of radiolabeled purified M-protein demon- 


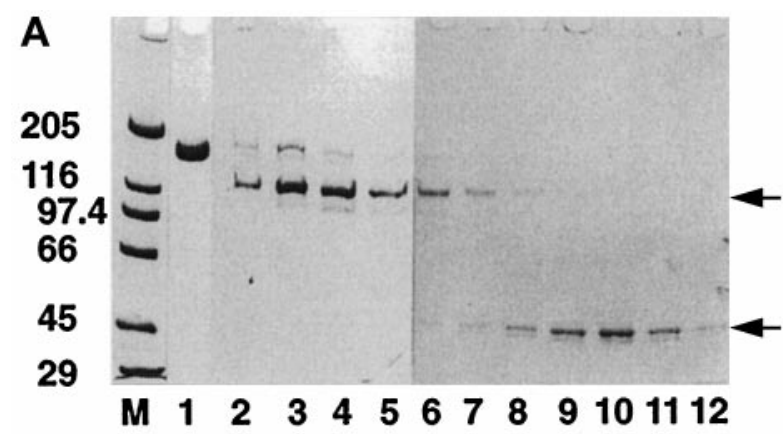

B

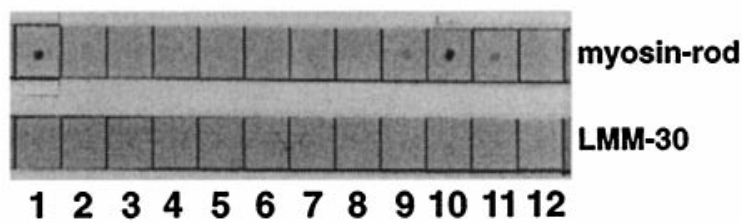

Figure 2. Binding of M-protein and its proteolytic 45-kDa fragment to myosin rod. (A) SDS-PAGE analysis (4-14\%) of M-protein purified from bovine skeletal muscle (lane 1) and gel filtration fractions of an endoproteinase Asp-N digest of M-protein (see MATERIALS AND METHODS) (lanes 2-12). $\mathrm{M}=$ molecular mass standards in kilodaltons. (B) M-protein (1) and corresponding fractions of the M-protein digest (2-12) spotted on nitrocellulose filters after incubation with biotinylated myosin-rod or LMM 30. Note that only native M-protein (1) and its 45-kDa fragment (comprising domains Mp2-Mp4; fractions 9-11) show binding to myosin rod, while the proteolytic $110-\mathrm{kDa}$ fragment of M-protein (comprising domains Mp5-Mp13; lanes 2-6) does not bind to myosin rod (the positions of these proteolytic fragments are indicated by arrows). Note also that both M-protein fragments do not bind to LMM30. Thus myosin rod binding of M-protein requires domains Mp2-Mp4.

strated that phosphorylation occurs exclusively on serine (Figure 4C).

For a detailed kinetic characterization of the potential PKA phosphorylation sites, we synthesized two peptides: LDEYASKKRASTQASSQ, corresponding to residues 29-45 of the human sequence, and RVCAKRVSTQEDEEQE, comprising residues 69-84 (Vinkemeier, et al., 1993). Both peptides were efficiently phosphorylated by PKA. The kinetics of the reaction were compared with the kinetics of the liver pyruvate kinase peptide LRRASLG ("kemptide"; Kemp et al., 1977) and a peptide from a region in myomesin, which is also phosphorylated by PKA (EKARLKSRPSAPWTGQ; Obermann et al., 1997). Table 1 shows that $K_{\mathrm{M}}$ values of both M-protein peptides were $\sim 1000 \mathrm{mM}$, which is approximately twice the $K_{\mathrm{M}}$ of the myomesin peptide. The $\mathrm{V}_{\max }$ was not determined in absolute numbers, since the concentration of PKA in the commercially available preparations could not be measured. Therefore, the numbers in Table 1 give relative units. Thus, the $\mathrm{V}_{\max }$ for the phosphorylation of the first M-protein peptide (LDEYASKKRASTQASSQ) is $\sim 30 \%$ of that of the myomesin peptide reaction, while
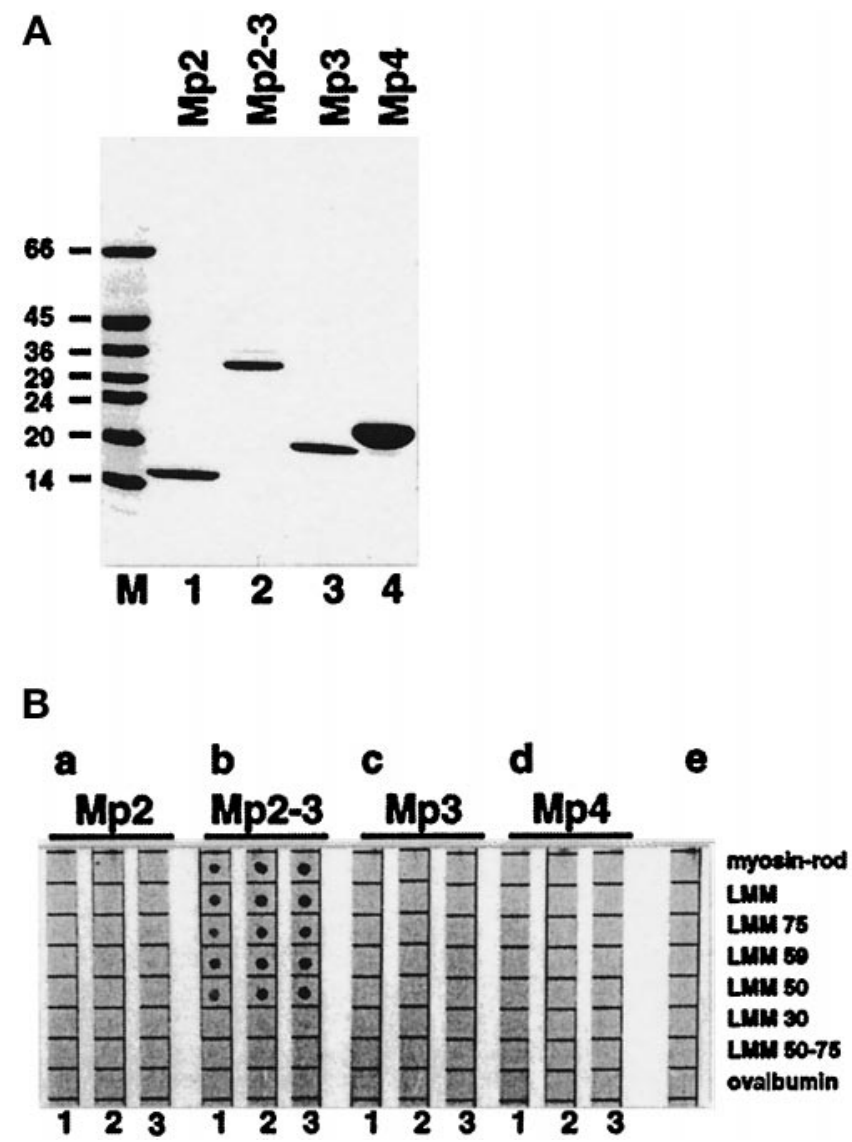

Figure 3. Binding of recombinant M-protein fragments to proteolytic and recombinant derivatives of myosin. (A) SDS-PAGE analysis $(6-20 \%$ gradient gels) of purified recombinant M-protein fragments: Mp2 (lane 1), Mp2-Mp3 (lane 2), Mp3 (lane 3), and Mp4 (lane 4). $\mathrm{M}=$ molecular mass standards in kilodaltons. For domain structure of M-protein see Figure 1. (B) Results of binding assays. The same amounts (ca. $1 \mu \mathrm{g}$ ) of myosin rod, proteolytic LMM, LMM 75, LMM 59, LMM 50, LMM 30, LMM 50-75, and ovalbumin, serving as a control, were spotted on nitrocellulose filters and overlaid with increasing concentrations $(1=0.5 \mu \mathrm{M}, 2=1.5 \mu \mathrm{M}, 3=4.5 \mu \mathrm{M})$ of M-protein fragments Mp2 (a), Mp2 to Mp3 (b), Mp3 (c), and Mp4 (d). (e) Control without protein in the overlay buffer. Binding of M-protein fragments carrying the carboxy-terminal EEF-tag was detected with monoclonal antibody YL1/2, which specifically recognizes this tag. Note the specific binding of M-protein fragment Mp2-Mp3 to all myosin fragments that contain the central portion of LMM (myosin heavy chain residues 1506-1674) but not to LMM30 and LMM50-75.

the $V_{\max }$ for the second M-protein peptide (RVCAKRVSTQEDEEQE) is $\sim 50 \%$.

To examine whether both sites are similarly recognized in the native M-protein molecule, several recombinant constructs were made in which either one (Ser39, Ser76) or both serine residues were mutated to alanine. Since the amino-terminal domain Mp1 alone remained entirely insoluble after expression in E. coli, larger constructs comprising domains $\mathrm{Mp} 1-\mathrm{Mp} 5$ were used. All recombinant proteins expressed in E. coli 
A

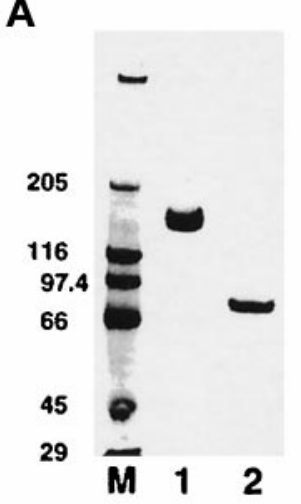

B
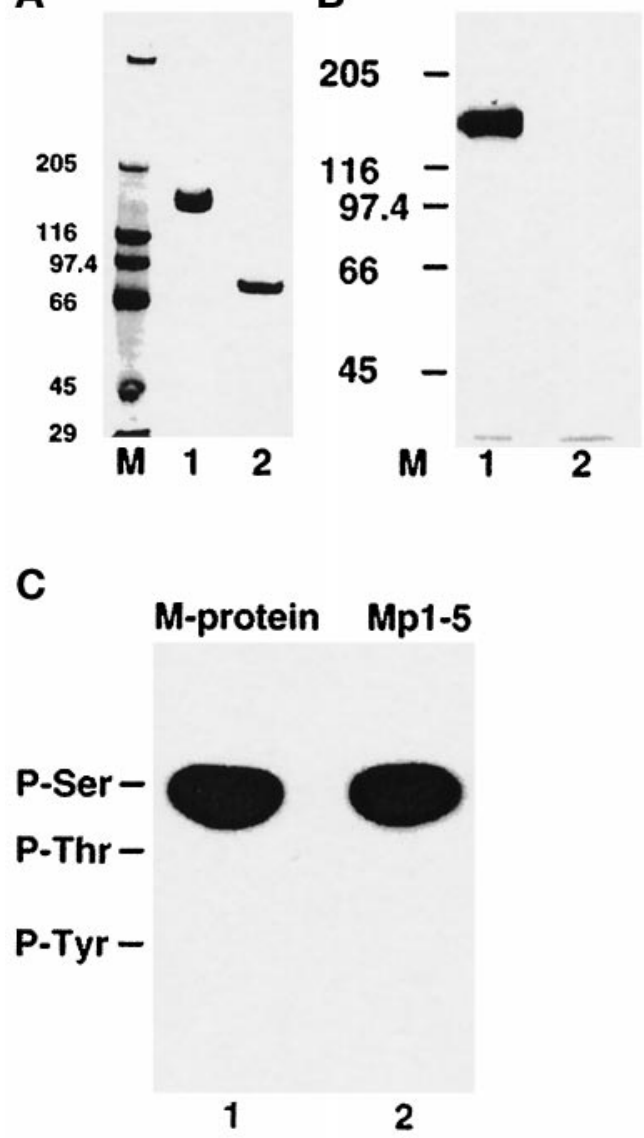

Figure 4. Phosphorylation of native M-protein and phosphoamino acid analysis of M-protein and a recombinant Mp1-5 fragment. (A) M-protein from bovine skeletal muscle (lane 1) and a limited digest with trypsin (lane 2), analyzed on $4-12 \%$ SDS-PAGE (see MATERIALS AND METHODS). (B) The corresponding autoradiograph of the samples shown in panel A after incubation with PKA in the presence of $\left[\gamma_{-}{ }^{32} \mathrm{P}\right]$ ATP shows that M-protein (lane 1) is readily phosphorylated while its tryptic fragment (Mp6-Mp13) is not (lane 2). $\mathrm{M}=$ molecular mass standards in kilodaltons. (C) Phosphoamino acid analysis of native M-protein from bovine skeletal muscle (lane 1) and the recombinant M-protein fragment Mp1-Mp5 (lane 2) after phosphorylation with PKA. Positions of marker amino acids are indicated. Clearly, phosphorylation occurs in both samples exclusively on serine residues.

were purified in the native state as described in MATERIALS AND METHODS. Phosphorylation was assayed by incubation with $\left[\gamma^{32} \mathrm{P}\right] \mathrm{ATP}$ in the presence of PKA, followed by SDS-PAGE and autoradiography. Figure 5 shows that both normal Mp1-5 and the mutant Mp1-5(Ser39Ala) were readily phosphorylated to comparable levels, while the mutant Mp1-5(Ser76Ala) and the double-mutant Mp1-5(Ser39, Ser76Ala) were essentially nonreactive. To determine the stoichiometry of the phosphorylation, the amount of phosphate incorporation into $\mathrm{M}$-protein and the recombinant protein fragments was compared by scintillation

Table 1. Phosphorylation of synthetic peptides by PKA ${ }^{a}$

\begin{tabular}{lrl}
\hline Peptide sequence & Apparent $K_{\mathrm{M}}$ & \multicolumn{1}{c}{$\mathrm{V}_{\max }$} \\
\hline LRRASLG & 16 & $20.2 \mathrm{mmol} \mathrm{min} \mathrm{mg}^{-1}$ \\
LKRASLG & 1400 & $17.1 \mathrm{mmol} \mathrm{min} \mathrm{mg}^{-1}$ \\
LRKASLG & 260 & $16.9 \mathrm{mmol} \mathrm{min} \mathrm{mg}^{-1}$ \\
& 14 & $266.4 \mathrm{cpm} / \mathrm{min}$ \\
LRRASLG & 532 & $130.9 \mathrm{cpm} / \mathrm{min}$ \\
EKARLKSRPSAPWTGQ & 993 & $42.0 \mathrm{cpm} / \mathrm{min}$ \\
LDEYASKKRASTQASSQ & 1027 & $66.5 \mathrm{cpm} / \mathrm{min}$ \\
RVCAKRVSTQEDEEQE & &
\end{tabular}

a The upper part of the table lists apparent $K_{M}$ and $V_{\max }$ values for a well characterized peptide substrate (kemptide) for PKA (Kemp et al., 1977) and two derivatives. The lower part summarizes our measurements using kemptide, a peptide from myomesin (see Obermann et al., 1996) and the two peptides from M-protein described in this study. Phosphorylation reactions were carried out as described in MATERIALS AND METHODS. Peptide sequences are given in column 1 .

counting. Again, only M-protein, "wild-type" Mp1-5, and the mutant Mp1-5(Ser39Ala) were phosphorylated at the same level $(0.97,0.95$, and $0.96 \mathrm{~mol}$ of phosphate per mol of protein, respectively), while both the other mutants were essentially negative (our unpublished results). Thus, it seems that in the native M-protein and in the fragment Mp1-5, serine 76 is the only substrate for PKA.

\section{Interaction of M-Protein with Myosin Is Modulated by PKA Phosphorylation}

Because the experiments described above delineate a myosin-binding site located in proximity of a target site for PKA (serine 76), we analyzed whether PKA phosphorylation of $\mathrm{M}$-protein influences the binding to myosin. In the binding assays, a series of proteolytic and recombinant myosin rod fragments were overlayed with purified bovine M-protein before or after PKA phosphorylation. Figure 6a shows that M-protein bound to the myosin rod derivatives exactly as described above for the proteolytic and recombinant fragments (Figures 2 and 3). On the other hand, phosphorylation of M-protein by PKA almost completely abolished the binding (Figure 6b).

Different myosin derivatives were also used to map the M-protein-binding site on the rod portion of myosin at greater precision. While proteolytic myosin rod, and proteolytic and recombinant LMM, as well as LMM 59 and LMM 50, were recognized by M-protein, LMM 50-75 and LMM 30 failed to bind M-protein (Figure 6a). We therefore conclude that the M-proteinbinding site on the myosin heavy chain is confined to the 169 amino acids between residues 1506 and 1674 located in the central part of LMM (numbers refer to 


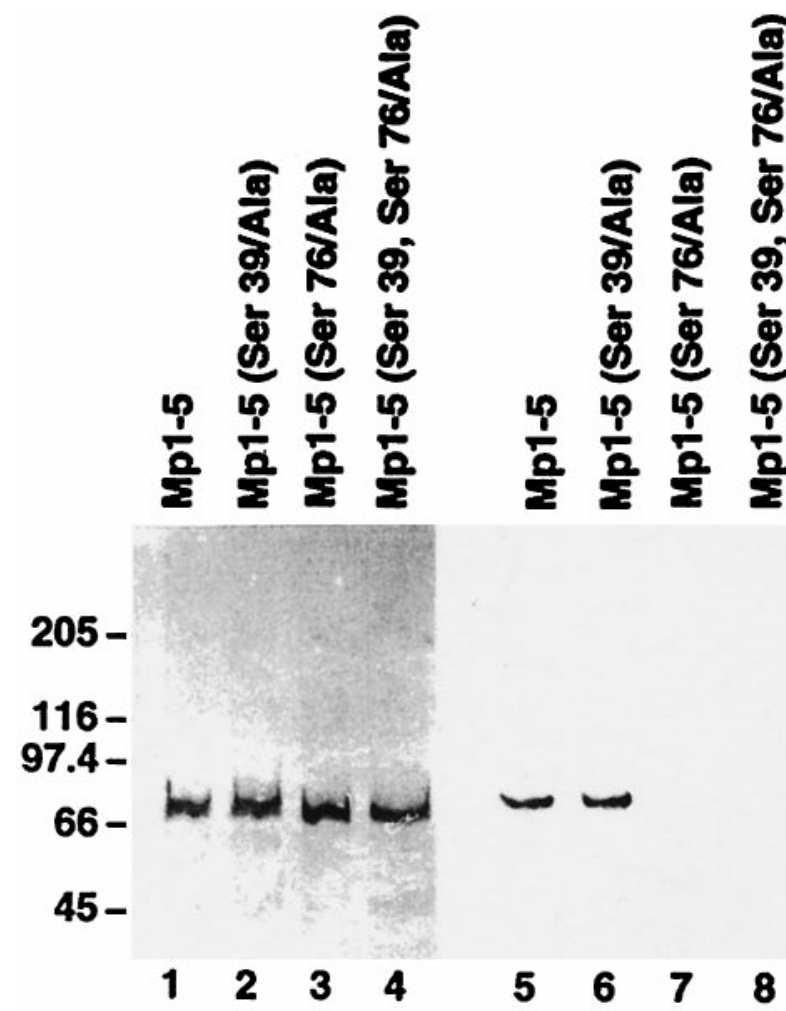

Figure 5. In vitro phosphorylation of mutant recombinant Mprotein fragments. Purified EEF-tagged Mp1-Mp5 fragments were phosphorylated in vitro by PKA and ${ }^{32} \mathrm{P}$-labeled ATP and run on two identical $4-10 \%$ gradient polyacrylamide gels. One gel was blotted to nitrocellulose and stained with the antibody recognizing the EEF-tag and a peroxidase-coupled secondary antibody (lanes 1-4), while the second gel was dried and autoradiographed (lanes 5-8). Lanes 1-4 contain approximately identical amounts of Mp1Mp5 (lane 1), Mp1-Mp5 (Ser39/Ala) (lane 2), Mp1-Mp5 (Ser76/ Ala) (lane 3), and Mp1-Mp5 (Ser39, 76/Ala) (lane 4). Lanes 5-8 show that Mp1-Mp5 and its (Ser39/Ala) mutant are phosphorylated, while phosphorylation of both mutants containing the Ser76/ Ala mutation (lanes 7 and 8 ) is almost completely abolished. Thus Ser76 is the PKA phosphorylation site of M-protein.

the amino acid sequence of rabbit fast skeletal muscle myosin heavy chain; see Maeda et al., 1987).

\section{Transfection of Cultured Cells}

To identify the regions of M-protein required for the incorporation of the molecule into the sarcomere, cultured cells were transfected with a series of constructs in the eukaryotic expression vector pCMV5-T7. The pCMV vector results in strong, constitutive expression of cDNAs in most eukaryotic cells under control of the cytomegalovirus promoter (Andersson et al., 1989). We replaced the original site for cloning foreign DNAs by introducing, immediately adjacent to the start codon, a new cassette containing recognition sites for the restriction enzymes BamHI, MluI, HindIII, SalI, and

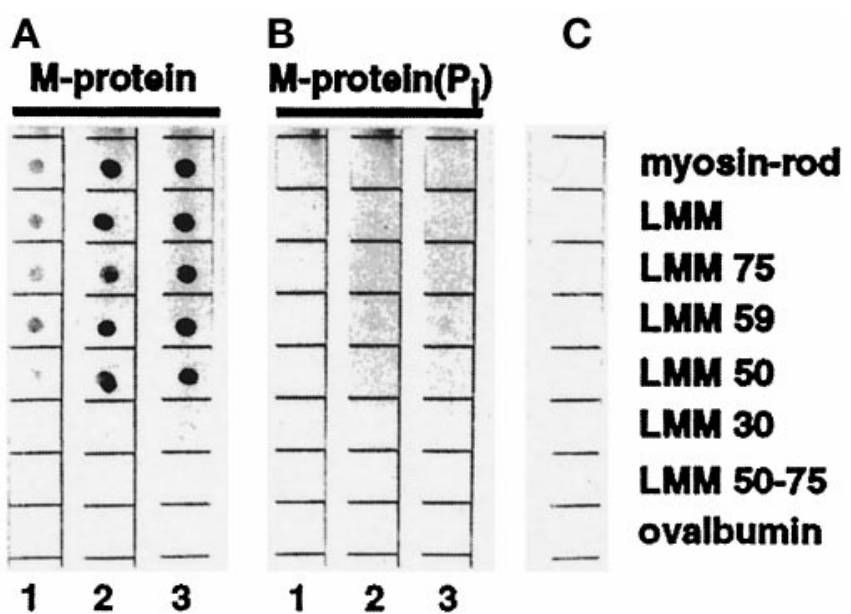

Figure 6. Interaction of unphosphorylated and PKA phosphorylated M-protein with proteolytic and recombinant derivatives of myosin. The same amounts $(1 \mu \mathrm{g})$ of myosin-rod, proteolytic LMM, LMM75, LMM59, LMM50, LMM30, LMM50-75, and ovalbumin, serving as a control, were spotted on nitrocellulose filters and overlayed with increasing concentrations $(1=0.1 \mu \mathrm{M}, 2=0.3 \mu \mathrm{M}$, $3=1.0 \mu \mathrm{M}$ ) of unphosphorylated (a) and phosphorylated (b) Mprotein. (c) is a control without protein. Binding of M-protein was detected using the monoclonal M-protein antibody MpAA280 (see Obermann, et al., 1996). Note that phosphorylation of M-protein almost completely abolished binding to myosin derivatives.

a sequence encoding the T7-tag, a 12-amino acid residue epitope (Lutz-Freyermuth et al., 1990; Tsai et al., 1992). Upon transfection, this results in the expression of a recombinant protein bearing at its carboxy terminus the T7-tag, which can be detected with a T7-tagspecific monoclonal antibody.

The effect of overexpression of specific portions of M-protein was studied mainly in BHK-21/C13 cells. These cells, which can be routinely transfected with high efficiency $(\sim 5-25 \%$, depending on the transfected construct), express already under certain culture conditions several sarcomeric proteins that assemble into myofibril-like structures (MLS). These resemble early myofibrils in "classical" muscle cells (Schaart et al., 1991; Van der Loop et al., 1996). Before the distribution and the effect of the M-protein constructs were studied, their correct expression was verified. At 24-40 h after transfection, cells were harvested in SDS-sample buffer and analyzed by Western blotting. In each case the T7 tag-specific antibody recognized a protein of the expected size. In addition, the correct expression was confirmed with domain-assigned antibodies for most of the constructs (our unpublished results).

Transfected cells were induced to differentiate and were inspected by immunofluorescence between 1 and $6 \mathrm{~d}$ later. To allow for a comparison with the internal sarcomeric cytoskeletal structures, the localization of T7-tagged proteins was usually compared with that of an epitope of titin located close to the A/I 

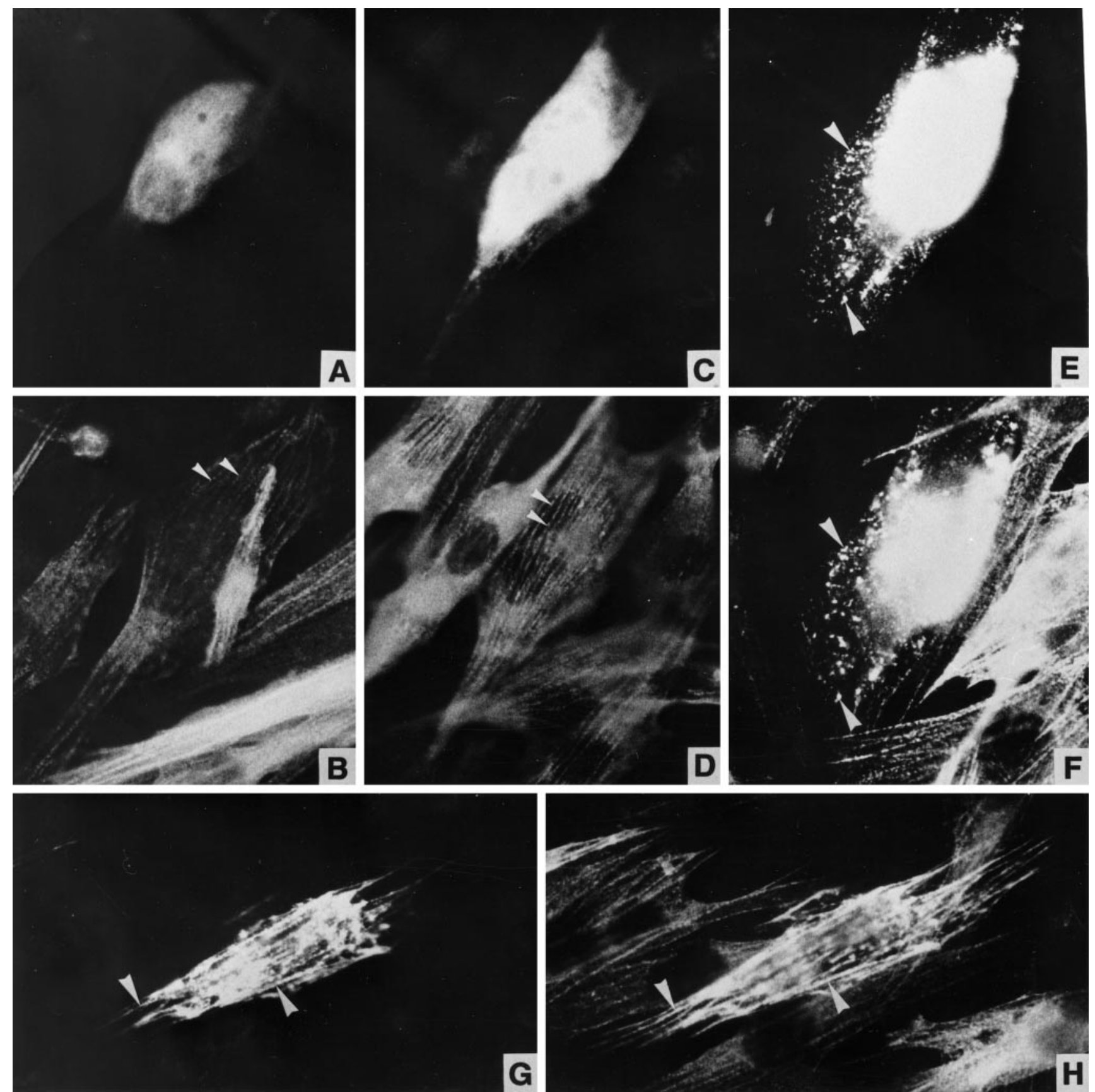

Figure 7. Expression of recombinant M-protein fragments in transiently transfected BHK-21/C13 cells. BHK-21/C13 cells transfected with constructs encoding Mp2 (A and B), Mp3 (C and D), or Mp2-Mp3 (E-H) were double stained with T7-tag antibody to localize the recombinant M-protein fragment (A, C, E, and G) and a titin antibody (B, D, F, and H). (A-D) Examples of transfected cells that contain large amounts of diffusely distributed recombinant protein (A and C) and titin, which appears in a normal staining pattern (arrowheads in B and D). The expressed Mp2-Mp3 construct either disrupts MLS, which then results in the appearance of numerous cytoplasmic aggregates containing both the recombinant protein and titin (arrowheads in E and F), or colocalizes with MLS (arrowheads in G and H). For details see RESULTS Magnification, 1050×.

junction. Figure $7(\mathrm{E}-\mathrm{H})$ shows that the construct comprising domains Mp2-Mp3 is localized primarily along MLS. In some cases, the recombinant protein was also revealed in dispersed cytoplasmic aggregates. In such cells, MLS were usually destroyed and the recombinant protein was found to colocalize with 
Table 2. Summary of the immunofluorescence patterns of cell transfection studies

\begin{tabular}{|c|c|c|c|c|c|c|}
\hline \multirow[b]{2}{*}{ Construct } & \multicolumn{2}{|c|}{$\begin{array}{l}\text { Association with } \\
\text { MLS/myofibrils }\end{array}$} & \multicolumn{2}{|c|}{$\begin{array}{l}\text { Disruption of } \\
\text { MLS/myofibrils }\end{array}$} & \multicolumn{2}{|c|}{ Nulcear localization } \\
\hline & BHK-21/C13 & $\mathrm{C} 2 \mathrm{C} 12$ & BHK-21/C13 & $\mathrm{C} 2 \mathrm{C} 12$ & BHK-21/C13 & $\mathrm{C} 2 \mathrm{C} 12$ \\
\hline Mp2 & - & - & - & - & - & - \\
\hline Mp3 & - & - & - & - & - & - \\
\hline Mp2-Mp3 & + & + & + & - & - & - \\
\hline Mp1-Mp3 & - & + & - & - & + & + \\
\hline Mp4-Mp8 & - & - & - & - & - & - \\
\hline Mp9-Mp13 & - & + & - & - & - & - \\
\hline
\end{tabular}

titin in these aggregates (Figure 7, E and F). In contrast, transfection with single domains (Mp2 containing the interdomain linker or Mp3) consistently resulted in a diffuse distribution of the expressed recombinant protein and a normal appearance of MLS (Figure 7, A-D; see also Table 2).

When cells were transfected with a construct comprising the unique amino-terminal domain Mp1 in addition to domains Mp2 and Mp3, the recombinant protein was recovered essentially in the nucleus (our unpublished results). A diffuse cytoplasmic distribution without obvious association with MLS was detected upon transfection with constructs encoding domains Mp4-Mp8 or Mp9-Mp13. In these cases we did not observe any destructive effects on MLS or a negative effect on the ability of the cells to differentiate (see Table 2).

To extend the results of the transfection studies with BHK cells, we also transfected C2C12 mouse myoblasts. Similar to the situation in BHK cells, an obvious colocalization of Mp2-Mp3 was found with nascent or mature myofibrils (Figure 8, A-D), while other constructs (e.g., Mp4-Mp8) showed a diffuse cytoplasmic localization (Table 2). Unlike in BHK cells, myofibril structure seemed not affected (Figure 8, B, D, and E). Surprisingly, Mp9-Mp13 was also distributed along filaments in a regular and discontinuous punctate pattern (Figure 8E). Inclusion of the head domain Mp1 into the construct Mp2-Mp3 typically resulted in a nuclear localization of the recombinant protein. In the few cases in which a cytoplasmic localization was also observed, the protein colocalized with stress fiber-like structures or myofibrils (Table 2). Both cell lines (BHK and C2C12) were also transfected with Mp1-Mp5 and the constructs in which either Ser39 or Ser76 was mutated to Ala (see above). In general, transfection efficiencies were very low in these experiments, and all resulting recombinant proteins showed almost exclusively nuclear localization (our unpublished results).

\section{DISCUSSION}

$\mathrm{M}$-protein is a prominent structural protein of sarcomeric $M$ bands in vertebrate fast and cardiac muscles (Perriard, 1993). Together with myomesin and titin, it forms the structures that cross-link myosin thick filaments in the central bare zone. We therefore started to search for binding sites between these proteins and their possible regulation.

Both limited proteolysis of purified M-protein and a series of recombinant constructs identified a myosin-binding site in domains Mp2-Mp3. Consistent with earlier observations (Mani and Kay, 1978; Woodhead and Lowey, 1983; Bähler et al., 1985) we found this interaction to be rather weak. It was best documented in solid-phase overlay assays (Figures 2,3 , and 6). The location of the myosin-binding site revealed an interesting difference between $\mathrm{M}$-protein and myomesin, the second major structural protein of the $\mathrm{M}$ band. Although both proteins share the same domain organization and exhibit 50\% identity over the repeat domains, their binding properties seem very different. Likewise, their structural organization within the sarcomeric $M$ band inferred by immunoelectron microscopy is different (Obermann et al., 1996). In myomesin the amino-terminal domain My1 seems to harbor the myosin-binding site (Obermann et al., 1997), while the subsequent pair of Ig domains Mp2-Mp3 shows myosin binding in the case of M-protein (Figure 3). In further experiments it was not possible to attribute the myosinbinding site to a single domain of M-protein. This observation resembles the situation found for the interactions of both myomesin and C-protein with titin. In both cases, constructs consisting of at least three domains were necessary to reveal binding of titin (Freiburg and Gautel, 1996; Obermann et al., 1997). Thus, it seems that the interactions of titin with other cytoskeletal proteins of the Ig superfamily binding arises by a combination of weak but 

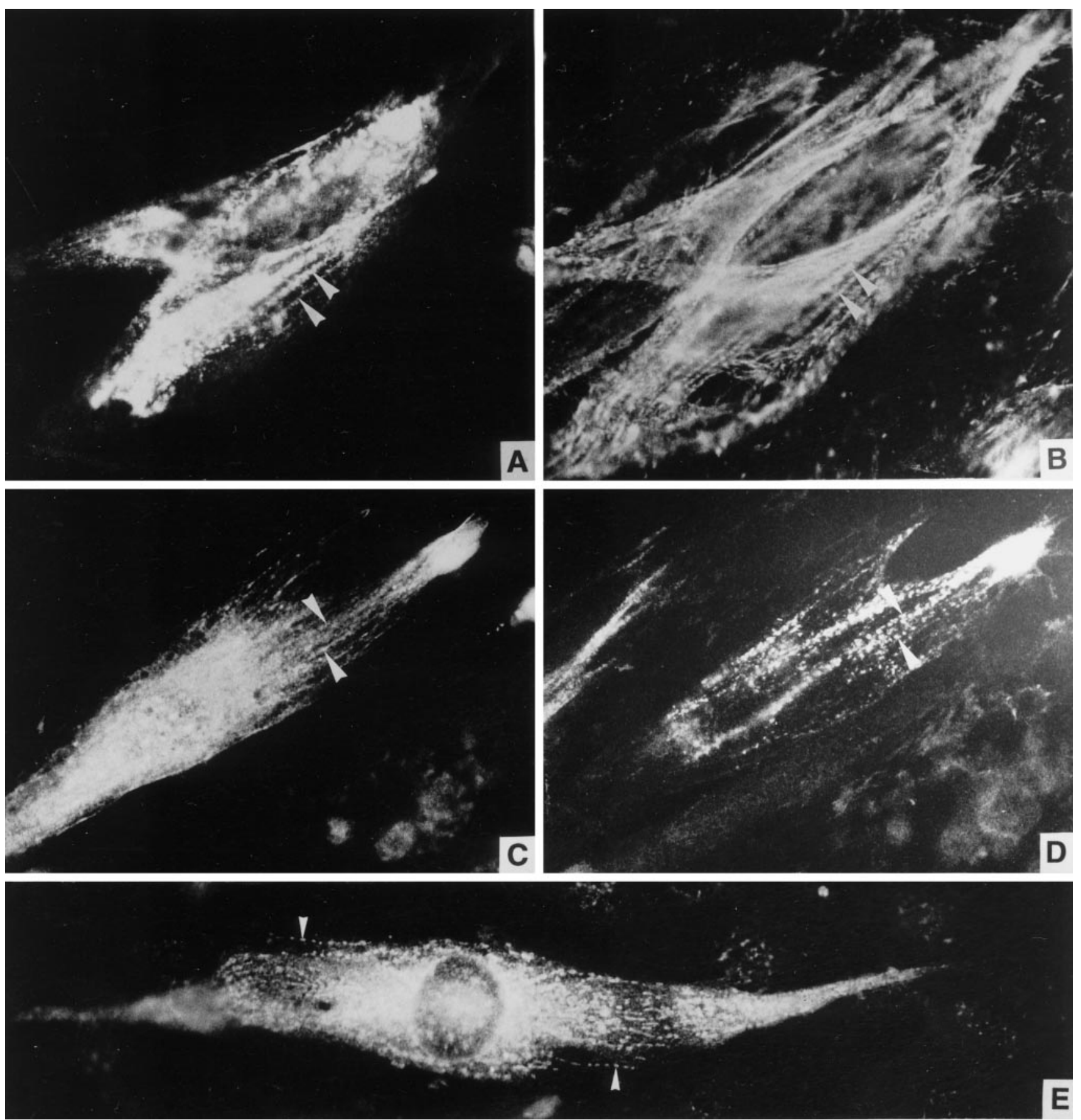

Figure 8. Expression of recombinant M-protein fragments in differentiating $\mathrm{C} 2 \mathrm{C} 12$ cells. $\mathrm{C} 2 \mathrm{C} 12$ cells transfected with constructs encoding T7-tagged Mp2-Mp3 (A-D) or Mp9-Mp13 (E) were allowed to differentiate for 2 (E) or 6 (A to D) d, respectively. Subsequently they were stained with T7-tag antibody (A, C, and E) and tetramethylrhodamine-5-isothiocyanate-labeled phalloidin (B) or MpAA259 (D) followed by secondary antibody. Note that most of the expressed Mp2-Mp3 polypeptide associates with myofibrils (arrowheads in A-D). Transfection with Mp9-Mp13 leads to expression of a polypeptide that binds to myofibrils in a periodic manner (arrowheads in E). For details see RESULTS. Magnification, 1050×.

cooperative interactions. It seems possible that a similar situation also holds for the interaction of M-protein and myosin.
Since the myosin-binding site of $\mathrm{M}$-protein (Mp2 plus Mp3) is adjacent to the unique amino-terminal domain Mp1 of the molecule, we investigated this 
molecular region in more detail. Computer analysis of the translated human M-protein cDNA sequence revealed two potential target sites for cAMP-dependent protein kinase A (Vinkemeier et al., 1993) in the peptides KKRAS* (residues 35-39) and KRVS* (residues 73-76). Indeed, purified M-protein can be specifically phosphorylated by PKA as well as by muscle extracts. Phosphorylation is serine specific and involves the amino-terminal domain Mp1 (Figure 4). Kinetic characterization of synthetic peptides encompassing both motifs demonstrated a $K_{\mathrm{M}}$ value in the range of $2 \times$ of that of a recently characterized PKA phosphorylation site in myomesin (Table 1; Obermann et al., 1997). The $\mathrm{V}_{\max }$ value is $\sim 50 \%$ of the same substrate. These values are within the range of other target sequences for PKA characterized previously (Pearson and Kemp, 1991). Analyses using recombinant M-protein fragments, in which either one or both of these serine residues were mutated to alanine, revealed that only serine residue 76 can be phosphorylated by PKA (Figure 5). This indicates that the three-dimensional structure of domain $\mathrm{Mp} 1$ in the native $\mathrm{M}$-protein molecule allows reactivity with PKA exclusively for Ser76. This result is made more significant by the finding that this site is well conserved between chicken (Noguchi et al., 1992) and human sequences (Vinkemeier et al., 1993).

The functional importance of this phosphorylation site is indicated by the finding that it seems to control the interaction of M-protein with myosin. Thus, while domains Mp2-Mp3 bind constitutively to myosin LMM, phosphorylation of Ser76 in the adjacent domain Mp1 modulates this binding. The phosphorylated fragment essentially lacks myosin binding. This may indicate complex changes of the three-dimensional structure of a larger molecular region of M-protein as the result of Ser 76 phosphorylation.

Earlier biochemical data indicate that M-protein also binds to titin (Nave et al., 1989). In our binding assays we have not yet been able to identify a titin-binding site in M-protein (our unpublished results). This is most likely due to the fact that our constructs did not cover the entire carboxy-terminal region of titin. In particular, the 500-residue insertion between Ig domains $\mathrm{m} 3$ and $\mathrm{m} 4$ (Gautel et al., 1993) was not included in the assay, since it could not be produced as recombinant protein (Gautel, personal communication). Our recent immunoelectron microscopical data, however, predict that this region of titin could be essential for M-protein binding (Obermann et al., 1996).

This study also demonstrates that recombinant constructs of M-protein can be efficiently incorporated into MLS after transient expression in differentiating BHK-21/C13 cells. These MLS were shown to resemble early myofibrils in standard differentiating muscle cells but offer many advantages in the handling of cells in culture and in their transfection efficiency (Schaart et al., 1991; Van der Loop et al., 1996). Immunofluorescence microscopy revealed that a construct comprising domains Mp2-Mp3 localized primarily to MLS in transfected cells (Figure 7 and Table 2). Thus it seems that the myosin-binding site of M-protein is involved in the specific targeting in the myofibril. Similar observations were made when $\mathrm{C} 2 \mathrm{C} 12$ mouse myoblast cells were transfected. While the construct Mp2-Mp3 was again found in nascent myofibrils, the fragment Mp4-Mp8 was distributed diffusely in the cytoplasm (Figure 8 and Table 2). Interestingly, the construct Mp9-Mp13 was also recovered in myofibrils (Figure 8 and Table 2). This indicates that in the carboxy-terminal third of M-protein, another myofibrillar binding site, possibly a titin-binding site (see above), can be expected.

The myosin-binding site in M-protein provides the second example of a protein-protein interaction in the sarcomeric $\mathrm{M}$ band whose binding status is controlled by PKA phosphorylation. For myomesin, phosphorylation was shown to regulate the binding to titin (Obermann et al., 1997). In both cases phosphorylation could provide a mechanism that controls the events during sarcomeric $\mathrm{M}$ band assembly, regeneration, and turnover in a spacial and temporal order. The binding of M-protein to myosin could be a mechanism necessary to provide a stronger thick filament association in myofibrils of fast and cardiac muscle fibers, since only these fibers of the adult animal express M-protein.

\section{ACKNOWLEDGMENTS}

We thank the following colleagues for valuable donations: Dr. V. Gerke (University of Münster, Munster, Germany) for the eukaryotic expression vector pCMV5, Dr. M. Greaser (University of Wisconsin-Madison, Madison, WI) for the titin monoclonal antibody 9D10, Dr. A. Wittinghofer (MPI for Molecular Physiology, Dortmund, Germany) for the LMM75 cDNA. P.v.d.V. acknowledges receipt of an European Molecular Biology Organization short-term fellowship and a fellowship from the Alexander-von-Humboldt foundation. This work was supported in part by grants from the Deutsche Forschungsgemeinschaft to D.O.F and K.W.

\section{REFERENCES}

Andersson, S., Davis, D.N., Dahlbäck, H., Jörnval, H., and Russel, D.W. (1989). Cloning, structure and expression of the mitochondrial cytochrome P-450 sterol 26-hydroxylase, a bile acid biosynthetic enzyme. J. Biol. Chem. 264, 8222-8229.

Ausubel, F.M., Brent, R., Kingston, R.E., Moore, D.D., Seidman, J.G., Smith, J.A., and Struhl, K. (1995). Short Protocols in Molecular Biology, 3rd ed., New York: Wiley and Sons, Inc.

Bähler, M., Wallimann T., and Eppenberger, H.M. (1985). Myofibrillar M-band proteins represent constituents of native thick filaments, frayed filaments and bare zone assemblages. J. Muscle Res. Cell Motil. 6, 783-800.

Carlsson, E., Grove, B.K., Wallimann, T., Eppenberger, H.M., and Thornell, L.-E. (1990). Myofibrillar M-band proteins in rat skeletal muscles during development. Histochemistry 95, 27-35.

Casnellie, J.E. (1991). Assay of protein kinases using peptides with basic residues for phosphocellulose binding. Methods Enzymol. 200, 115-120. 
Freiburg, A., and Gautel, M. (1996). A molecular map of the interactions of titin and myosin-binding protein $\mathrm{C}$ : implications for sarcomeric assembly in familial hypertrophic cardiomyopathy. Eur. J. Biochem. 235, 317-323.

Fürst, D.O., Osborn, M., Nave, R., and Weber, K. (1988). The organization of titin filaments in the half-sarcomere revealed by monoclonal antibodies in immunoelectron microscopy; a map of ten non-repetitive epitopes starting at the $\mathrm{Z}$ line extends close to the $\mathrm{M}$ line. J. Cell Biol. 106, 1563-1572.

Fürst, D.O., Osborn, M., and K. Weber. (1989). Myogenesis in the mouse embryo: differential onset of expression of myogenic proteins and the involvement of titin in myofibril assembly. J. Cell Biol. 109, 517-527.

Gautel, M., Leonard, K., and Labeit, S. (1993). Phosphorylation of KSP motifs in the C-terminal region of titin in differentiating myoblasts. EMBO J 12, 3827-3834.

Grove, B.K., Cerny, L., J.-Perriard, C., and Eppenberger, H.M. (1985). Myomesin and M-protein: Expression of two M-band proteins in pectoral muscle and heart during development. J. Cell Biol. 101, 1413-1421.

Grove, B.K., Holmbom, B., and L.-Thornell, E. (1987). Myomesin and $\mathrm{M}$ protein: differential expression in embryonic fibers during pectoral muscle development. Differentiation 34, 106-114.

Grove, B.K., Kurer, V., Lehner, C., Doetschmann, T.C., Perriard, J.-C., and Eppenberger, H.M. (1984). A new 185,000-dalton skeletal muscle protein detected by monoclonal antibodies. J. Cell Biol. 98, 518-524.

Kemp, B.E., Graves, D.J., Benjamini, E., and Krebs, E.G. (1977). Role of multiple basic residues in determining the substrate specifity of cyclic AMP-dependent protein kinase. J. Biol. Chem. 251, 4888-4894.

Laemmli, U.K. (1970). Cleavage of structural proteins during the assembly of the head of bacteriophage T4. Nature 227, 680-685.

Luther, P.K., and Squire, J.M. (1978). Three -dimensional structure of the vertebrate muscle M-region. J. Mol. Biol. 125, 313-324.

Lutz-Freyermuth, C., Query, C.C., and Keene, J.D. (1990). Quantitative determination that one of two potential RNA-binding domains of the A protein component of the U1 small nuclear ribonucleoprotein complex binds with high affinity to stem-loop II of U1 RNA. Proc. Natl. Acad. Sci. USA 87, 6393-6397.

Maeda, K., Sczakiel, G., and Wittinghofer, A. (1987). Characterization of cDNA coding for the complete light meromyosin portion of a rabbit fast skeletal muscle myosin heavy chain. Eur. J. Biochem. 167, 97-102.

Mani, R.S., and Kay, C.M. (1978). Interaction studies of the 165,000 dalton protein component of the M-line with the S2 subfragment of myosin. Biochim. Biophys. Acta 536, 134-141.

Masaki, T., and Takaiti, O. (1974). M-protein. J. Biochem. 75, 367380 .

Nave, R., Fürst, D.O., and Weber, K. (1989). Visualization of the polarity of isolated titin molecules; a single globular head on a long thin rod as the M-band anchoring domain? J. Cell Biol. 109, 2177-2188.

Noguchi, J., Yanagisawa, M., Imamura, M., Kasuya, Y., Sakurai, T., Tanaka, T., and Masaki, T. (1992). Complete primary structure and tissue expression of chicken pectoralis M-protein. J. Biol. Chem. 267, 20302-20310.

Obermann, W., Plessmann, U., Weber, K., and Fürst, D.O. (1995). Purification and biochemical characterization of myomesin, a myosin and titin binding protein, from bovine skeletal muscle. Eur. J. Biochem. 233, 110-115.

Obermann, W.M.J., Gautel, M., Steiner, F., Van der Ven, P.F.M., Weber, K., and Fürst, D.O. (1996). The structure of the sarcomeric M band: localization of defined domains of myomesin, M-protein and the $250 \mathrm{kDa}$ carboxyterminal region of titin by immunoelectron microscopy. J. Cell Biol. 134, 1441-1453.

Obermann, W.M.J., Gautel, M., Weber, K., and Fürst, D.O. (1997). Molecular structure of the sarcomeric M band: mapping of titin- and myosin-binding domains of myomesin and the identification of a potential regulatory phosphorylation site in myomesin. EMBO J. 16, 211-220.

Pearson, R.B., and Kemp, B.E. (1991). Protein kinase phosphorylation site sequences and consensus specifity motifs: tabulations. Methods Enzymol. 201, 62-81.

Perriard, J.-C. (1993). Myomesin and M-protein. In Guidebook to the Cytoskeletal and Motor Proteins, ed. T. Kreis and R. Vale, Oxford, England: Oxford University Press, 58-59.

Saiki, R.K., Scharf, S.J., Faloona, F., Mullis, G.T., and Ehrlich, H.A. (1985). Enzymatic amplification of beta-globin genomic sequences and restriction site analysis for diagnosis of sickle cell anemia. Science 230, 1350-1354

Sambrook, J., Fritsch, E.F., and Maniatis, T. (1989). Molecular Cloning: A Laboratory Manual. Cold Spring Harbor, NY: Cold Spring Harbor Laboratory Press.

Schaart, G., Pieper, F.R., Kuijpers, H.J.H., Bloemendal, H., and Ramaekers, F.C.S. (1991). Baby hamster kidney (BHK-21/C13) cells can express striated muscle type proteins. Differentiation 46, 105-115.

Small, J.V., Fürst, D.O., and Thornell, L.-E. (1992). The cytoskeletal lattice of muscle cells. Eur. J. Biochem. 208, 559-572.

Studier, F.W., Rosenberg, A.H., Dunn, J.J., and Dubendorff, J.W. (1990). Use of T7 RNA polymerase to direct expression of cloned genes. Methods Enzymol. 185, 60-89.

Tsai, D.E., Kenan, D.J., and Keene, J.D. (1992). In vitro selection of an RNA epitope immunologically cross-reactive with a peptide. Proc. Natl. Acad. Sci. USA 89, 8864

Van der Loop, F.T.L., Van der Ven, P.F.M., Fürst, D.O., Gautel, M., Van Eys, G.J.J.M., and Ramaekers, F.C.S. (1996). Integration of titin into the sarcomeres of cultured differentiating human skeletal muscle cells. Eur. J. Cell Biol. 69, 301-307.

Van der Ven, P.F.M., Schaart, G., Croes, H.J.E., Jap, P.H.K., Ginsel, L.A., and Ramaekers, F.C.S. (1993). Titin aggregates associated with intermediate filaments align along stress fiber-like structures during human skeletal muscle cell differentiation. J. Cell Sci. 106, 749-759.

Vinkemeier, U., Obermann, W., Weber, K., and Fürst, D.O. (1993). The globular head domain of titin extends into the center of the sarcomeric M band. J. Cell Sci. 106, 319-330.

Wallimann, T., Doetschman, T.C., and Eppenberger, H.M. (1983). Novel staining pattern of skeletal muscle M-lines upon incubation with antibodies against MM-creatine kinase. J. Cell Biol. 96, 17721779.

Wallimann, T., and Eppenberger, H.M. (1985). Localization and function of M-line-bound creatine kinase. Cell Muscle Motil. 6, 239-285.

Wang, S.M., and Greaser, M.L. (1985). Immunocytochemical studies using a monoclonal antibody to bovine cardiac titin on intact and extracted myofibrils. J. Muscle Res. Cell Motil. 6, 293-312.

Wehland, J., Schröder, H.C., and Weber, K. (1984). Amino sequence requirements in the epitope recognized by the the a-tubulin-specific rat monoclonal antibody YL 1/2. EMBO J. 3, 1295-1300.

Wessel, D., and Flügge, U.J. (1984). A method for the quantitative recovery of protein in dilute solution in the presence of detergents and lipids. Anal. Biochem. 138, 141-143.

Woodhead, J.L., and Lowey, S. (1983). An in vitro study of the interactions of skeletal muscle M-protein and creatine kinase with myosin and its subfragments. J. Mol. Biol. 168, 831-846. 